\title{
THE ASSESSMENT OF THE OCCURRENCE OF BENIGN HYPERMOBLLITY JOINT SYNDROME IN PHYSIOTHERAPY STUDENTS
}

\author{
Ewelina Żyżniewska-Banaszak, 1, A, B, D Hanna Tchórzewska-Korba, 2, A \\ Magdalena Gębska, , , C, D Katarzyna Weber-Nowakowska, ${ }^{1, B}$ K Katarzyna Leźnicka, , , C, D \\ Kuba Żyżniewskit, A, D \\ ${ }^{1}$ Department of Physical Therapy and Biological Rejuvenation, Pomeranian Medical University, Szczecin, Poland \\ 2 University of Social Sciences, Faculty of Medical Sciences, Warsaw, Poland \\ ${ }^{3}$ Department of Human Functional Anatomy and Biometry, Faculty of Physical Culture and Health Promotion, Szczecin University, Szczecin, \\ Poland \\ ${ }^{4}$ Student Scientific Society of Physiotherapists and Manual Therapists at the Department of Physical Therapy and Biological Rejuvenation, \\ Pomeranian Medical University, Szczecin, Poland

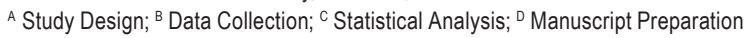

\section{Address for correspondence:} \\ Katarzyna Leźnicka \\ University of Szczecin, Faculty of Physical Culture and Health Promotion, Department of Human Functional Anatomy and Biometry \\ Al. Piastów 40b, 71-065 Szczecin, Poland \\ E-mail: k.leznicka@tlen.pl
}

\begin{abstract}
Ahstract The occurrence of connective tissue disorders is an important factor for development of occupational diseases in professions requiring a non-ergonomic and often static load of the musculoskeletal system. Symptoms of the connective tissue disorders appear at different ages. The diagnosis of hypermobility is an important problem due to the lack of uniform diagnostic criteria.

The aim of this paper is to evaluate the incidence of joint hypermobility and its relation with a history of injuries and the level of physical activity in Physiotherapy students.

The study involved 143 students ( $69 \%$ female, $31 \%$ male) aged 18 to 27 years ( $M=20.7 ; S D=1.43)$. The assessment of the occurrence of Benign Hypermobility Joint Syndrome (BHJS) syndrome was performed using the Beighton and Brighton scale. Among the surveyed students almost $82 \%$ of the women and just over $18 \%$ of the men fulfilled the diagnostic criteria for the diagnosis of hypermobility. A significant difference was also observed in the physical activity of the students. Among those who showed no signs of hypermobility exactly half of the participants trained sports as amateurs, while in the group of people with hypermobility the proportion was lower by nearly half. BHJS was not related to injuries and operations in the study group.
\end{abstract}

Key WOrds hypermobility, joint, Beighton score, score Brighton, sports, physiotherapy

\section{Introduction}

Hypermobility of the joints, also known as "double-jointedness" is characterized by bigger than normal range of motion in the joints (Seçkin et al., 2005; Yazgan, Geyikli, Zeyrek, Baktiroglu, Kurcer, 2008). The mobility of the 
joints changes with age. These changes do not occur simultaneously and with the same intensity in each joint. The largest mobility of the joints is in infants and decreases with time at varying rates. The joint mobility decreases very rapidly during childhood and more slowly in adolescents and adults (Malfait, Hakim, De Paepe, Grahame, 2006).

Hypermobility is a symptom of disorder in the structure of the connective tissue associated with a number of genetic diseases for example Osteogenesis Imperfecta, Down's syndrome, Marfan's syndrome, Ehler-Danlos syndrome and BHJS. Originally BHJS was named the hypermobility syndrome (HMS), first described by Kirk, Ansell, Bywaters (1967) as a pathological condition characterized by excessive joint mobility along with additional symptoms from the musculoskeletal system. In adults the symptoms of musculo - skeletal disorders resulting from excessive mobility of joints were described as the Hypermobility Syndrome (HS).

In the scientific reports the terms Joint Hipermobility Syndrome (JHS) and BHJS are used interchangeably (Simmonds, Keer, 2007). The term constitutional hypermobility (CM) is also sometimes used referring to a generalized and innate connective tissue deficiency of the whole body assessed by the Brighton scale.

The major manifestations of CM include increased joint mobility, softness of joint capsules and ligaments (lomdina et al., 2015). Other symptoms including ease of dislocations and joint sprains, muscle and joint pain, hyperelastic skin, vision disorders, disorders of the gut, problems with body stabilization and other Brighton criteria indicate the presence of BHJS. CM is mainly observed in the developmental and in young adults. With age the joint mobility decreases, however, it is related to the aging process of the body and not to the disappearance of abnormal connective tissue.

Excessive joint mobility is observed in approximately $10 \%$ of "healthy" people, especially among Asians, is present more often in women than in men (Larsson, Baum, Mudholkar, 1987; Moraes, Louzada, 2007). Excessive joint mobility often predisposes to choose a profession where it can be useful. This applies to acrobats, ballet dancers and musicians playing various instruments such as the violin and the piano (Grahame, Jenkins, 1997; Larsson, Baum, Mudholkar, Kollia, 1993).

The occurrence of connective tissue disorders is an important factor in occupational diseases in groups of professions requiring a non-ergonomic and often static load. It is the cause of micro-injuries and later the cause of disorders of the musculoskeletal system in office workers, IT specialists, dentists, drivers, athletes etc. The presence of dysfunction resulting from the occurrence of benign joint hypermobility syndrome can be used to take preventive measures for vulnerable occupational groups.

In the available medical literature, a large role is assigned to health prevention (Pate et al., 1995; Penedo, Dahn, 2005). Particular attention is given to physical activity as an important factor in maintaining health (Warburton, Nicol, Bredin, 2006). This includes, but is not limited to, people with evidence of constitutional hypermobility (CM). Although exercise will not help to achieve better "stiffness" in stretched tendons or ligaments, it is advisable to strengthen the muscle strength and proprioception. Improperly dosed movement is a cause of musculoskeletal and other ailments. It should be noted that the treatment of people with CM is exclusively symptomatic. Personalized exercises can strengthen weakened muscles by improving the stabilization of excessively moving joints, thereby reducing their soreness. In order to improve stability, mainly exercises in closed kinematic chains should be implemented (Gębska, Weber-Nowakowska, Żółtowska, Żyżniewska-Banaszak, Woitas-Ślubowska, 2017). Due to the consequences that hypermobility can cause, the assessment of the predispositions that point out existing BHMJ allows targeted therapy of people with hypermobility. It is important to inform students of medical and related fields of possibilities of counteracting the symptoms of HS and to present methods of rehabilitation in situations 
where there is risk of injury, specially that the dysfunction of the musculoskeletal system caused by the presence of hypermobility significantly increases the risk of many diseases within the musculoskeletal system.

The aim of the study was to assess the prevalence of joint hypermobility and its relation with a history of injuries and the level of physical activity in physiotherapy students.

\section{Materials and methods}

The research was conducted among physiotherapy students at the Faculty of Health Sciences of the Pomeranian Medical University in Szczecin. The study involved 143 students (69\% of women, $31 \%$ of men) aged 18-27 years $(M=20.7, S D=1.43)$. Body weight and body height of all of the participants was measured using an electronic scales.

\section{Subjective examination}

The subjective examination included a questionnaire containing questions about personal factors, social factors, current health, level of physical activity and details about past injuries.

\section{Assessment of Benign Hypermobility Joint Syndrome incidence}

In order to determine the occurrence of joint hypermobility in the participants of this study a 9-point Beighton test was performed. It consists of: a passive extension of the fifth finger above $90^{\circ}$, passive thumb adduction to the inner surface of the forearm, elbow joint overextension above $10^{\circ}$, overextension of the knee above $10^{\circ}$, placing the whole surface of the hands on the ground while standing with straight knee joints (Table 1).Obtaining a minimum of 4 points in the test is the basis for the diagnosis of HS. Subsequently, the Brighton test was conducted in order to diagnose BHJS.

Tahle 1. Beighton test

\begin{tabular}{|c|c|c|c|}
\hline No. & Joint movement examined & $\begin{array}{c}\text { Right side } \\
\text { (0-1 points) }\end{array}$ & $\begin{array}{c}\text { Left side } \\
\text { (0-1 points) }\end{array}$ \\
\hline 1. & The ability to position your hand flat on the floor during the while standing with straight knees. & & \\
\hline 2. & Passive hyperextension of the fifth finger above $90^{\circ}$ & & \\
\hline 3. & Passive adduction of the thumb to the surface of the forearm. & & \\
\hline 4. & Hyperextension of the elbow & & \\
\hline 5. & Hyperextension of the knee joint & & \\
\hline SUM & & & \\
\hline
\end{tabular}

The Beighton test result included the results of the Brighton test and symptoms such as arthralgia, degenerative spine conditions, joint subluxation, skin symptoms, eyesight disorders, hernias, varicose veins, anal fissures, and body type. The criteria were divided into "large criteria" and "small criteria" (Table 2). The basis for the diagnosis of BHJS is: the presence of at least two "high criteria", a "big" and two "small" or four "small" (Bisaralli, Kanti Dutta, Flora Marak, Naorem, 2017; Pacey, Nicholson, Adams, Munn, Munns, 2010). 
Table 2. Brighton criteria

\begin{tabular}{|c|c|c|c|}
\hline 1 & LARGE CRITERIA & Yes & No \\
\hline 1. & 4 or more points on the Beighton scale (currently or in the past) & & \\
\hline 2. & Pain in at least 4 joints that lasts at least 3 months & & \\
\hline$\|$ & SMALL CRITERIA & & \\
\hline 1. & Result $=1,2,3$ in the Beighton scale & & \\
\hline 2. & $\begin{array}{l}\text { Pain in } 1 \text { to } 3 \text { joints lasting longer than } 3 \text { months, or back pain lasting } 3 \text { or more months, spondylosis, } \\
\text { spondylolysis /spondylolisthesis }\end{array}$ & & \\
\hline 3. & History of joint displacement or subluxations in more than 1 joint or more than 1 time & & \\
\hline 4. & Soft tissue rheumatism (3 months or more) (e.g. Epicondylitis,tenosynovitis, bursitis) & & \\
\hline 5. & Marfanoid appearance, Arachnodactyly (+ Steinberg symptom) & & \\
\hline 6. & Irregularities affecting the skin - stretch marks, hyperelastic skin, thin skin & & \\
\hline 7. & Ocular symptoms: ptosis, myopia, antimongoloid slant & & \\
\hline 8. & Varicose veins of the lower limbs, hernias, anal or vaginal/ uterus prolapse & & \\
\hline \multirow{4}{*}{\multicolumn{2}{|c|}{$\begin{array}{l}\text { Benign Hypermobility Joint Syndrome: } \\
\text { - at least two "big" criteria } \\
\text { - one "big" and two "small" criteria } \\
\text { - four „small" criteria }\end{array}$}} & BHJS & \\
\hline & & Score: & \\
\hline & & & \\
\hline & & & \\
\hline
\end{tabular}

All participants have signed a consent to participate in this study. The study was approved by the Bioethical Committee of the Regional Medical Chamber in Szczecin (KB-0012/104/15).

\section{Statistical analysis}

The statistical analysis was done in the IBM SPSS V.21 packet. The Pearson Chi-square test, the nonparametric Mann-Whiteney test and the binary logistics regression analysis were used. The value of $p<0.05$ was assumed to be significant and the value of $p<0.1$ was assumed to be an indicator of a non-significant statistical trend.

\section{Resullts}

Among the examined students almost $82 \%$ of women and only slightly over $18 \%$ of men met the diagnostic criteria for the diagnosis of hypermobility. A significant difference was also observed in the physical activity of the students. A significant difference was also observed in the physical activity of the students. Among those who showed no signs of hypermobility exactly half of the participants trained sports as amateurs, while in the group of people with hypermobility the proportion was lower by nearly half. BHJS was not related to injuries and operations in the study group (Table 3).

Comparative analysis of examined students with BHJS and without BHJS revealed significant differences in body weight, body height and BMI between these groups (Table 4).

In the next step, all the variables that coexisted with hypermobility were collected in one regression model to determine whether estimating the risk of hypermobility by the gender, BMI and additional physical activity of young adults was possible (Table 5). 
Table 3. Characteristics of the group by selected dichotomous variables including hypermobility; N (\%)

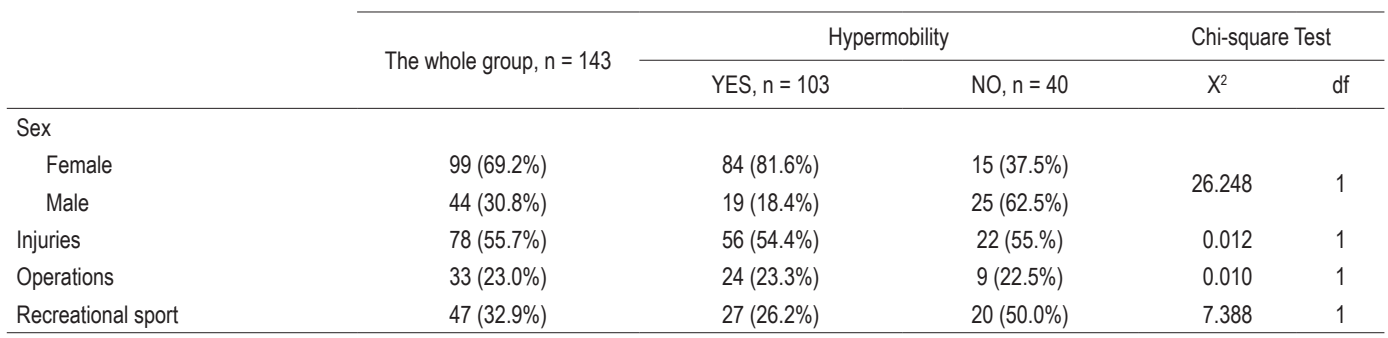

Table 4. Characteristics of the group by selected quantitative variables including hypermobility; M (SD)

\begin{tabular}{lcccc} 
& \multirow{2}{*}{ The whole group, $n=143$} & \multicolumn{2}{c}{ Hypermobility } & \multicolumn{2}{c}{ Mann-Whiteney U Test } \\
\cline { 3 - 5 } & $20.70(1.43)$ & YES, $n=103$ & NO, $n=40$ & -1.740 \\
\hline Age & $65.86(13.15)$ & $20.56(1.35)$ & $21.08(1.60)$ & -4.444 \\
Body mass & $172.28(8.99)$ & $169.95(8,33)$ & $75.55(12.89)$ & -4.965 \\
Height & $22.03(2.97)$ & $21.39(2,79)$ & $178.26(7.87)$ & -4.156 \\
BMl & & $23.65(2.82)$ & \\
\hline
\end{tabular}

Tahle 5. Binary logistics regression analysis of hypermobility predictors

\begin{tabular}{lrrrrrrrrr} 
& B & S.E. & Wald & df & p & Exp(B) & \multicolumn{2}{c}{$95 \%$ C.I } \\
\cline { 6 - 9 } & & & & & & & Lower & Upper \\
\hline Sex & 1.463 & 0.452 & 10.491 & 1 & 0.001 & 4.320 & 1.782 & 10.473 \\
Physical activity & -0.786 & 0.441 & 3.183 & 1 & 0.074 & 0.455 & 0.192 & 1.081 \\
BMl & -0.188 & 0.078 & 5.772 & 1 & 0.016 & 0.829 & 0.711 & 0.966 \\
Constant & 4.566 & 1.910 & 5.718 & 1 & 0.017 & 96.189 & & \\
\hline
\end{tabular}

The most important of the hypermobility predictors was the sex - the likelihood of finding hypermobility among women is 4.3 times higher than in men. A significant relationship also exists with BMI which is also related to the gender. The exp value (B) indicates that with the decrease of BMI by 1 compartmental point, the probability that the participant meets the criteria for hypermobility increased by about $0.8 \%$.

There is an incomplete relation with the physical activity of the participants. Those practicing amateur sport are in the risk of hypermobility of almost $46 \%$ greater than those not practicing sports.

\section{Discussion}

The diagnosis of hypermobility is an important problem due to the lack of uniform diagnostic criteria. Symptoms of hypermobility appear at different ages (3-55 years). Most cases occur before the age of 15 . Symptoms of hypermobility are more common in females and concern the lower limbs more often, which manifests itself, for example, with proneness to ankle and knee sprains (Seçkin et al., 2005). Joint hypermobility decreases with age, and it seems to be related to gender and race (Beighton, Grahame, Bird, 1989). The authors research has shown 
that in as many as $82 \%$ of students of physiotherapy symptoms of BHJS can be found using the Beighton and Brighton tests. In men this percentage was about $18 \%$. In medical literature there are many studies that show that sex is one of the main factors predisposing to the development of BHJS (Larsson et al., 1987; Moraes, Louzada, 2007).

By analyzing the results from the interview card, it is clear that $55.02 \%$ of students do not know whether they are hypermobile, and only $9.46 \%$ recognize the ailment in themselves. This fact proves that there is a lack of knowledge of hypermobility of joints and the risks that it carries in future physiotherapists. Hypermobile joints are always overloaded, leading to adverse biomechanical changes in the body's motion such as faster wear of joint surfaces, overloads, and pain.

Among the participants, the diagnosed group with BHJS differed significantly in body weight and height compared to those without BHJS. The fact is confirmed by numerous scientific reports, where people with BJHS are overweight, suffer from chronic joint pain and other neuromusculoskeletal symptoms associated with collagen defects (Everman, Robin, 1998; Finsterbush, Pogrund, 1982).

The purpose of increased physical activity with a clear predominance of exercises focusing on suppleness is to increase the mobility and flexibility in the joints. It contributes to reducing the intensity and incidence of injuries and is one of the main factors protecting against joint damage. Depending on needs, suppleness is interchangeable named as flexibility or elasticity. Its basic measure is the amplitude or the range of movement of the selected joints, which depend on the structure of passive joint structures such as the joint surfaces, joint capsules and ligaments, and the active joint structures - the muscles (Cromie, Robertson, Best, 2000). The biggest diagnostic problem concerns people who have an increased range of motion in the joints as the result of many years of training (gymnastics, dance) and persons subjected to heavy physical loads (professional athletes) (McCormack, Briggs, Hakim, Grahame, 2004; Pacey et al., 2010). Excessive flexibility may seem to be an advantage in sports such as gymnastics, dance, acrobatics, and a potential risk in such disciplines as rugby, judo (and other martial arts) where athletes have significantly different sensitivity to pain compared to non-athletes (Stewart, Burden, 2004; Leźnicka, Pawlak, Białecka, Safranow, Cięszczyk, 2017). Many authors suggest that frequent sports injuries are caused by excessive motion in the joints (Smith, Damodaran, Swaminathan, Campbell, Barnsley, 2005). In people with BHJS who do not suffer from pain Simmonds, Keer (2007) recommend a non-contact sport, such as swimming, Pilates and tai chi, while Murray (2006) recommends full involvement in sport. In a study performed on rowers and swimmers, the percentage of athletes with hypermobility in rowers who in training rely on performing repetitive movements in closedkinematic chains is smaller than in swimmers (Gębska et al., 2016). In ourstudy, among the students who have no symptoms of hypermobility, exactly half of the practiced sports recreationally, while in the group of people with hypermobility only $26.2 \%$ undertook physical activity. This observation confirms the association of BHJS with motor activity. People with hypermobility are much more likely to drop out of physical activity most likely because of the pain that occurs during or after exercise. Physiotherapists should be physically fit because the nature of the work requires high quality motor features such as strength, power, coordination, balance and endurance. Assuming long lasting, monotonous, non-ergonomic and uncomfortable positions while performing rehabilitation treatments such as massage, lifting and verticalization leads to the occurrence of dysfunctions and disorders of the musculoskeletal system (Bash, Farber, 1999; Passier, McPhail, 2011). In the case of hypermobility of the joints, the physiotherapist's physical strain can lead to traumas and overload of the locomotor system, resulting in degenerative changes and disability. 


\section{Conclusion}

In the study group hypermobility was not related to injuries and operations. The knowledge of physiotherapy students with the characteristics of hypermobility is insufficient, which should be taken into account when training future physiotherapists. The eligibility criteria to become a physiotherapist should include the diagnosis for benign joint hypermobility syndrome.

Special training programs for people with hypermobility should be developed and implemented to protect joints from overload. The implementation of prevention and rehabilitation in the early stages of the dysfunction will help prevent the occurrence of locomotor disorders in the medical profession.

\section{References}

Bash, D.S., Farber, R.S. (1999). An examination of self-reported carpal tunnel syndrome symptoms in hand therapists, protective and corrective measures and job satisfaction. Work, 13, 75-82.

Beighton, P.H., Grahame, R., Bird, H. (1989). Hypermobility of Joints. 2nd ed. London (UK): Springer-Verlag.

Bisaralli, R., Kanti Dutta, P., Flora Marak, A., Naorem, S. (2017). Benign joint hypermobility syndrome: A case series. J Med Soc, 1 (31), 59-62.

Cromie, J.E., Robertson, V.J., Best, M.O.(2000). Work-related musculoskeletal disorders in physical therapists: prevalence, severity, risks, and responses. Phys Ther, 80, 336-351.

Everman, D.B., Robin, N.H. (1998). Hypermobility syndrome. Pediatr Rev,19, 111-117.

Finsterbush, A., Pogrund, H. (1982). The hypermobility syndrome. Clin Orthop Relat Res, 168, 124-127.

Gębska, M., Weber-Nowakowska, K., Oklejak, M., Boćkowski, R., Żyżniewski, K., Żyżniewska-Banaszak, E. (2016). Polyarticular hypermobility and its consequences in rowers and swimmers: a preliminary report. TSS, 3, 141-145.

Gębska, M., Weber-Nowakowska, K., Żółtowska, O., Żyżniewska-Banaszak, E., Woitas-Ślubowska, D. (2017). Deep stabilization muscles training in patients with polyarticular hypermobility. J. Educ. Health Sport, 9 (7), 101-135.

Grahame, R., Jenkins, J.M. (1972). Joint hypermobility - asset or liability? A study of joint mobility in ballet dancers. Ann Rheum Dis, $31,109-111$.

Iomdina, E., Tarutta, E., Markossian, G., Aksenova, J., Smirnova, T., Bedretdinov, A. (2015) Sclera as the target tissue in progressive miopia. Pomeranian J Life Sci, 2 (61),146-152.

Kirk, J.A., Ansell, M., Bywaters, E.G.L.(1967). The hypermobility syndrome. Ann Rheum Dis, 26, 419-425.

Larsson, L.G., Baum, J., Mudholkar, G.S. (1987). Hypermobility features and differential incidence between sexes. Arthritis Rheum, 30, 1426-14230.

Larsson, L.G., Baum, J., Mudholkar, G.S., Kollia, G.D. (1993). Benefits and disadvantages of joint hypermobility among musicians. N Engl J Med, 7, 1120-1181.

Leźnicka, K., Pawlak, M., Białecka, M., Safranow, K., Cięszczyk, P. (2017). Pain perception and cardiovascular system response among contact sport athletes. Res Sports Med, 3 (25), 290-299.

Malfait, F., Hakim, A.J., De Paepe, A., Grahame, R. (2006). The genetic basis of the joint hypermobility syndromes. Rheumatology, 45, 502-504.

McCormack, M., Briggs, J., Hakim, A., Grahame, R. (2004). Joint laxity and the benign joint hypermobility syndrome in student and professional ballet dancers. J Rheumatol, 1 (31),173-178.

Moraes, D.A., Louzada, P.Jr. (2007). Joint hypermobility diagnosis and prevalence in the Brazilian university students. Ann Rheum Dis, 66 (suppl. II), 250.

Murray, K.J. (2006). Hypermobility disorders in children and adolescents. Best Pract \&Res Clin Rheumatol, 20, 329 Y 51.

Pacey, V., Nicholson, L.L., Adams, R., Munn, J., Munns, C.F. (2010). Generalized joint hypermobility and risk of lower limb joint injury during sport : a systematic review with meta-analysis. Am J Sports Med, 38, 1487-1497. DOI: 10.1177/0363546510364838.

Passier, L., McPhail, S. (2011). Work related musculoskeletal disorders amongst therapists in physically demanding roles: qualitative analysis of risk factors and strategies for prevention. BMC Musculoskelet Disord, 12, 24. 
Penedo, F., Dahn, J.R. (2005). Exercise and well-being: a review of mental and physical health benefits associated with physical activity. Current Opinion in Psychiatry, 2 (18), 189-193.

Pate, R.R., Pratt, M., Blair, S.N., Haskell, W.L., Macera, C.A, Bouchard, C., Buchner, D., Ettinger, W. et.al. (1995). Physical Activity and Public Health A Recommendation From the Centers for Disease Control and Prevention and the American College of Sports Medicine. JAMA, 5 (273), 402-407. DOI: 10.1001/jama.1995.03520290054029.

Seçkin, Ü., Sonel, B., Yılmaz, Ö., Yağci, I., Bodur, H., Arasil, T. (2005). The prevalence of joint hypermobility among high school students. Rheumatol Int, 25, 260-263.

Simmonds, J., Keer, R. (2007). Hypermobility and the hypermobility syndrome. Man Ther, 12, 298-309. DOI: 10.1016/j.math.2007.05.001.

Smith, A.K., Damodaran, S., Swaminathan, R., Campbell, R., Barnsley, L. (2005). Hypermobility and sports injuries in junior netball players. Br J Sports Med, 39, 628-631. DOI: 10.1136/bjsm.2004.015271.

Stewart, D.R., Burden, S.B. (2004). Does generalised ligamentous laxity increase seasonal incidence of injuries in male first division club rugby players? Br. J. Sports Med, 38, 457-460. DOI: 10.1136/bjsm.2003.004861.

Warburton, D.E., Nicol, C.W., Bredin, S.S. (2006).Health benefits of physical activity: the evidence. CMAJ, 6 (174). DOI: 10.1503/ cmaj.051351.

Yazgan, P., Geyikli, I., Zeyrek, D., Baktiroglu, L., Kurcer, M.A. (2008). Is joint hypermobility important in prepubertal children? Rheumatol Int, 5 (28), 445-451.

Cite this anticle aS: Żyżniewska-Banaszak, E., Tchórzewska-Korba, H., Gębska, M., Weber-Nowakowska, K., Leźnicka, K., Żyżniewski, K. (2017). The Assessment of the Occurrence of Benign Hypermobility Joint Syndrome in Physiotherapy Students. Central European Journal of Sport Sciences and Medicine, 4 (20), 23-30. DOI: 10.18276/cej.2017.4-03. 